\title{
Lactic Acidosis Induced by Linezolid Mimics Symptoms of an Acute Intracranial Bleed: A Case Report and Literature Review
}

\author{
Nichole Suzzanne Zuccarini ${ }^{a}$, ${ }^{\text {, Tariq Yousuf }}{ }^{\mathrm{b}}$, Daniel Wozniczka ${ }^{\mathrm{b}}$, Anis Abdul Rauf
}

\begin{abstract}
Lactic acidosis is common and most often associated with disturbed acid-base balance. Rarely, it can be a life-threatening medication side effect. Hence, determining the etiology of lactic acidosis early in patients is paramount in choosing the correct therapeutic intervention. Although lactic acidosis as an adverse drug reaction of linezolid is a well-recognized and documented clinical entity, the occurrence of such mimicking an acute intracranial bleed has not been reported to our knowledge. The following case is presented as an example of such an occurrence. A 67-year-old woman presented to the emergency department for lethargy, nausea and syncope. The head CT did not demonstrate any bleeding or mass effect, but lab results were significant for elevated lactic acid. The patient recently underwent left total hip replacement surgery, which was complicated by a methicillinresistant Staphylococcus aureus (MRSA) infection. She received 6 weeks of oral linezolid therapy. And upon learning that key part of her history, the linezolid was discontinued. Her lactic acid rapidly normalized and she was discharged home. Several publications demonstrate that linezolid induces lactic acidosis by disrupting crucial mitochondrial functions. It is essential that clinicians are aware that linezolid can cause lactic acidosis. And, the important reminder is that adverse drug reactions can often mimic common diseases. If it is not recognized early, ominous clinical consequences may occur. In conclusion, linezolid should be suspected and included in the differential diagnosis if lactic acidosis exists with an uncommon clinical picture.
\end{abstract}

Keywords: Lactic acidosis; Linezolid; Mitochondrial dysfunction; Drug-induced mitochondrial dysfunction; Electron transport chain

Manuscript accepted for publication August 08, 2016

a Department of Internal Medicine, AMITA Health Adventist Medical Center, Hinsdale, 911 N Elm St \#102, Hinsdale, IL 60521; University of Medicine and Health Sciences, New York, NY, USA

${ }^{b}$ Department of Internal Medicine, Advocate Christ Medical Center, $4440 \mathrm{~W}$ 95th Street, Oak Lawn, IL 60453, USA

'AMITA Health Adventist Medical System, Bolingbrook, Glen Oaks, Hinsdale, La Grange, 911 N Elm St \#102, Hinsdale, IL 60521, USA

${ }^{\mathrm{d} C}$ Corresponding Author: Nichole Suzzanne Zuccarini, Department of Internal Medicine, AMITA Health Adventist Medical Center, Hinsdale, 911 N Elm St \#102, Hinsdale, IL 60521; University of Medicine and Health Sciences, New York, NY, USA. Email: nzuccarini@umhs-sk.net

doi: http://dx.doi.org/10.14740/jocmr2687w

\section{Introduction}

Lactic acidosis is common and most often associated with disturbed acid-base balance. Determining the etiology of lactic acidosis early in patients is paramount in choosing the correct therapeutic intervention [1,2]. Lactic acid exists in two optical isomeric forms, L-lactate and D-lactate. Additionally, the condition of lactic acidosis has been divided into two categories, type A and type B. L-lactate is the only form produced in human metabolism, which is also most commonly measured in the laboratory. Excess L-lactate represents tissue hypoperfusion. Conversely, D-lactate is produced by bacteria with the ability to produce it from carbohydrates. It can accumulate in patients suffering from short-gut syndrome due to gastric bypass or small-bowel resections [3]. The category of type A lactic acidosis is defined by the disturbances related to tissue hypoperfusion, whereas type B lactic acidosis is defined by preexisting conditions like alcoholism, kidney or liver failure, and malignancies. Drug-induced disorders are also included within the type B realm. There is a well-known list of medications that cause lactic acidosis, most noticeably nucleoside reverse transcriptase inhibitors and biguanides [3, 4]. Rarely, linezolid, part of the oxazolidinone class of antimicrobials, has been linked to fatal lactic acidosis [1, 2]. Linezolid was FDA approved in 2000 for use in treating methicillin-resistant Staphylococcus aureus (MRSA), vancomycin-resistant $E$. fecalis infections, and mycobacterial infections as a secondline therapy. Linezolid is a bacteriostatic antimicrobial that works by binding to $23 \mathrm{~S}$ ribosomal RNA residues of the $50 \mathrm{~S}$ large subunit on bacterial ribosomes, thereby inhibiting bacterial protein synthesis [3]. The side effect of linezolid leading to lactic acidosis is rare, $<1 \%$, and the mechanism involves disruption of several mitochondrial functions [1-43]. Although lactic acidosis as an adverse drug reaction of linezolid is a well-recognized and documented clinical entity, the occurrence of such mimicking an acute intracranial bleed has not heretofore been reported to our knowledge. The following case is presented as an example of such an occurrence.

\section{Case Report}

A 67-year-old woman with a past medical history significant for hypertension, dyslipidemia, and bilateral avascular necrosis of the femoral head presented to the emergency department 
for syncope. Her husband explained that she was attempting to use the toilet in the morning, passed out, and hit her head. Patient was noted to be extremely lethargic and vomiting upon examination. The head CT did not demonstrate any bleeding or mass effect. However, the lab results were significant for high lactic acid (9.4), thrombocytopenia, anemia, hyponatremia, and hypokalemia. Immediate volume resuscitation was started with sodium chloride $0.9 \%$ and potassium chloride additive. Her second set of laboratory values still demonstrated lactic acidosis, but now with slightly improved electrolytes. Unquestionably, a deeper look into the patient's history was needed. Her husband mentioned she had a left total hip replacement approximately 3 months earlier, but was unable to provide many details. Consequently, her medical records were obtained and reviewed thoroughly. The team identified her left total hip replacement was complicated by a post-operative MRSA infection. A peripherally inserted central catheter line was placed and she received 6 weeks of intravenous vancomycin therapy. Then, she was weaned off and switched to oral linezolid for another 6 weeks. Based on those key findings, the linezolid was immediately discontinued. In under $6 \mathrm{~h}$, her lactic acid levels dropped by half. During rounds the next morning, she reported no nausea or vomiting, had increased strength and requested a bowl of cereal. Her electrolytes and lactic acid slowly normalized and she was discharged home. Based upon these significant events, linezolid was officially documented as an adverse reaction in her chart.

\section{Discussion}

The clinical condition presented above likely was an adverse drug reaction due to the chronological association with linezolid use, improvement of patient condition after discontinuation of the drug, and lack of an alternative explanation [43]. One could argue that she presented with anemia, which could have created a low oxygen state in the tissues, causing lactic acidosis and her symptom profile. However, this is unlikely because when linezolid was discontinued, her lactic acid levels and symptoms improved even though her anemia was still present. Other arguments could be that she might have been taking other medications, had underlying undiagnosed diabetes, or been ingesting ethanol, which might have contributed to her lactic acidosis. But, her glucose was normal, ethanol and toxicology screens were negative and none of the other medications she received were known to cause lactic acidosis. Additionally, her kidney and liver function was in question as a possible cause for lactic acidosis at first, but quickly proved to be functioning normally based on repeated laboratory values.

Several recent publications demonstrated linezolid causes lactic acidosis by disrupting crucial mitochondrial functions [1-43]. For example, skeletal muscle at autopsy was sampled from a 64-year-old man who died in the ICU with suspected linezolid-induced lactic acidosis. The case report substantiated lactic acidosis developed in the skeletal muscle sample during continuous infusion of linezolid, while oxygen consumption and oxygen extraction were diminishing. Also, electron trans- port chain complexes I, III, and IV, encoded by nuclear and mitochondrial DNA, demonstrated low activity, but complex II, which is encoded by nuclear DNA only, had normal functionality. And, there was a reduction in compensatory mitochondrial biogenesis and adaptive unfolded protein response. The study concluded that linezolid-induced lactic acidosis demonstrated reduced oxygen consumption and extraction, effecting mitochondrial protein translation, mitochondrial biogenesis and unfolded protein response [1]. Polymorphisms of mitochondrial DNA have also been hypothesized to increase the susceptibility of certain individuals to the toxic effects of linezolid $[36,41]$. Moreover, decreased activity of the mitochondrial respiratory complex IV was revealed via measurements in peripheral mononuclear cells from three patients who developed lactic acidosis while receiving linezolid therapy [42]. Remarkably, discontinuation of linezolid has uniformly demonstrated sufficient resolution of lactic acidosis midst patients who survived the event. If more acute treatment measures need to be taken, dialysis and administration of electron transport chain cofactors have been minimally successful $[41,37]$.

The woman in this case presented with syncope, a traumatic fall, and symptoms resembling an intracranial bleed or mass. Additional factors that could mislead clinicians towards that diagnosis were compounded due to her history of dyslipidemia and hypertension. The only presenting contradictory evidence was elevated lactic acid and minor electrolyte imbalances. Nonetheless, the turning point for this patient occurred after gaining knowledge from her prior medical records. A high index of suspicion leading to learning about her total hip replacement and MRSA complications helped save her life. Furthermore, it is essential clinicians are aware that linezolid can cause lactic acidosis, and be mindful that adverse drug reactions often mimic common diseases. If it is not recognized early, ominous clinical consequences may occur. In conclusion, linezolid should be suspected and included in the differential diagnosis if lactic acidosis exists with an uncommon clinical picture.

\section{Conflicts of Interest}

No authors involved in this case report have any potential conflicts of interest.

\section{Grant Support}

None.

\section{References}

1. Protti A, Ronchi D, Bassi G, Fortunato F, Bordoni A, Rizzuti T, Fumagalli R. Changes in Whole-Body Oxygen Consumption and Skeletal Muscle Mitochondria During Linezolid-Induced Lactic Acidosis. Crit Care Med. 2016;44(7):e579-582.

2. Djibre M, Pham T, Denis M, Pras Landre V, Fartoukh M. 
Fatal lactic acidosis associated with linezolid therapy. Infection. 2015;43(1):125-126.

3. Uribarri J, Oh MS, Carroll HJ. D-lactic acidosis. A review of clinical presentation, biochemical features, and pathophysiologic mechanisms. Medicine (Baltimore). 1998;77(2):73-82.

4. Carrico AW. Elevated suicide rate among HIV-positive persons despite benefits of antiretroviral therapy: implications for a stress and coping model of suicide. Am J Psychiatry. 2010;167(2):117-119.

5. Bassetti M, Righi E. Safety profiles of old and new antimicrobials for the treatment of MRSA infections. Expert Opin Drug Saf. 2016;15(4):467-481.

6. Johnson PC, Vaduganathan M, Phillips KM, O'Donnell WJ. A triad of linezolid toxicity: hypoglycemia, lactic acidosis, and acute pancreatitis. Proc (Bayl Univ Med Cent). 2015;28(4):466-468.

7. Im JH, Baek JH, Kwon HY, Lee JS. Incidence and risk factors of linezolid-induced lactic acidosis. Int J Infect Dis. 2015;31:47-52.

8. Flanagan S, McKee EE, Das D, Tulkens PM, Hosako H, Fiedler-Kelly J, Passarell J, et al. Nonclinical and pharmacokinetic assessments to evaluate the potential of tedizolid and linezolid to affect mitochondrial function. Antimicrob Agents Chemother. 2015;59(1):178-185.

9. Hsu SN, Shih MF, Yang CW, Wu CC, Chen CC. Severe linezolid-induced lactic acidosis in a cirrhosis patient. Nephrology (Carlton). 2015;20(1):47-48.

10. Hall RG, 2nd, Michaels HN. Profile of tedizolid phosphate and its potential in the treatment of acute bacterial skin and skin structure infections. Infect Drug Resist. 2015;8:75-82.

11. Kishor K, Dhasmana N, Kamble SS, Sahu RK. Linezolid Induced Adverse Drug Reactions - An Update. Curr Drug Metab. 2015;16(7):553-559.

12. Iragavarapu $\mathrm{C}$, Gupta $\mathrm{T}$, Chugh SS, Aronow WS, Frishman WH. Type B Lactic Acidosis Associated With Venlafaxine Overdose. Am J Ther. 2016;23(4):e1082-1084.

13. Ozkaya-Parlakay A, Kara A, Celik M, Ozsurekci Y, Karadag Oncel E, Ceyhan M, Cengiz AB. Early lactic acidosis associated with linezolid therapy in paediatric patients. Int J Antimicrob Agents. 2014;44(4):334-336.

14. Sawyer AJ, Haley HL, Baty SR, McGuffey GE, Eiland EH, 3rd. Linezolid-induced lactic acidosis corrected with sustained low-efficiency dialysis: a case report. Am J Kidney Dis. 2014;64(3):457-459.

15. Ozkaya-Parlakay A, Kara A. Lactic acidosis as an early side effect of linezolid therapy in pediatric patients. Pediatr Infect Dis J. 2014;33(8):890-891.

16. Del Pozo JL, Fernandez-Ros N, Saez E, Herrero JI, Yuste JR, Banales JM. Linezolid-induced lactic acidosis in two liver transplant patients with the mitochondrial DNA A2706G polymorphism. Antimicrob Agents Chemother. 2014;58(7):4227-4229.

17. Kraleti S, Soultanova I. Pancytopenia and lactic acidosis associated with linezolid use in a patient with empyema. J Ark Med Soc. 2013;110(4):62-63.

18. Miyawaki A, Ueda T, Nakao A, Adachi M, Ohya M, Yamada I, Takesue Y, et al. Linezolid-induced lactic acidosis followed by severe hypophosphatemia after discontinuation of linezolid. Surg Infect (Larchmt). 2013;14(2):229230.

19. Rose PC, Hallbauer UM, Seddon JA, Hesseling AC, Schaaf HS. Linezolid-containing regimens for the treatment of drug-resistant tuberculosis in South African children. Int J Tuberc Lung Dis. 2012;16(12):1588-1593.

20. Cope TE, McFarland R, Schaefer A. Rapid-onset, linezolid-induced lactic acidosis in MELAS. Mitochondrion. 2011;11(6):992-993.

21. Su E, Crowley K, Carcillo JA, Michaels MG. Linezolid and lactic acidosis: a role for lactate monitoring with long-term linezolid use in children. Pediatr Infect Dis J. 2011;30(9):804-806.

22. Contou D, Fichet J, Grimaldi D, Cariou A. Early lifethreatening lactic acidosis following a single infusion of linezolid. Int J Antimicrob Agents. 2011;38(1):84-85.

23. Carbajo T, Fenollosa M, Pons R, Calvo C. Lactic acidosis and linezolid-induced pancytopaenia. Nefrologia. 2011;31(1):107-108.

24. De Bus L, Depuydt P, Libbrecht L, Vandekerckhove L, Nollet J, Benoit D, Vogelaers D, et al. Severe drug-induced liver injury associated with prolonged use of linezolid. J Med Toxicol. 2010;6(3):322-326.

25. Prieto de Paula JM, Franco Hidalgo S, Mayor Toranzo E, Gutierrez PP. [Mixed, and not just lactic, acidosis in a patient on linezolid]. Enferm Infecc Microbiol Clin. 2010;28(7):481-482.

26. Velez JC, Janech MG. A case of lactic acidosis induced by linezolid. Nat Rev Nephrol. 2010;6(4):236-242.

27. Rachoin JS, Weisberg LS, McFadden CB. Treatment of lactic acidosis: appropriate confusion. J Hosp Med. 2010;5(4):E1-7.

28. Fernandez de Orueta L, Diaz V, Ramirez M, Alvarez R. [Linezolid-induced lactic acidosis]. Enferm Infecc Microbiol Clin. 2009;27(9):550-551.

29. Boutoille D, Grossi O, Depatureaux A, Tattevin P. Fatal lactic acidosis after prolonged linezolid exposure for treatment of multidrug-resistant tuberculosis. Eur J Intern Med. 2009;20(6):e134-135.

30. Lee YR, Powell N, Bonatti H, Sawyer RG, Barroso L, Pruett TL, Sifri CD, et al. Early development of lactic acidosis with short term linezolid treatment in a renal recipient. J Chemother. 2008;20(6):766-767.

31. Scotton P, Fuser R, Torresan S, Carniato A, Giobbia M, Rossi C, Inojosa WO, et al. Early linezolid-associated lactic acidosis in a patient treated for tuberculous spondylodiscitis. Infection. 2008;36(4):387-388.

32. Quintana-Ortiz RA, Gomez MA, Baez Feliciano DV, Hunter-Mellado RF. Suicide attempts among Puerto Rican men and women with HIV/AIDS: a study of prevalence and risk factors. Ethn Dis. 2008;18(2 Suppl 2):S2219-224.

33. Wiener M, Guo Y, Patel G, Fries BC. Lactic acidosis after treatment with linezolid. Infection. 2007;35(4):278-281.

34. Carson J, Cerda J, Chae JH, Hirano M, Maggiore P. Severe lactic acidosis associated with linezolid use in a patient with the mitochondrial DNA A2706G polymorphism. Pharmacotherapy. 2007;27(5):771-774. 
35. Baez-Feliciano DV, Quintana R, Gomez MA, Fernandez DM, Velazquez M, Olivares E, Leon Valiente C, et al. Trends in the HIV and AIDS epidemic in a Puerto Rican cohort of patients: 1992-2005. Bol Asoc Med P R. 2006;98(3):174-183.

36. Palenzuela L, Hahn NM, Nelson RP, Jr., Arno JN, Schobert C, Bethel R, Ostrowski LA, et al. Does linezolid cause lactic acidosis by inhibiting mitochondrial protein synthesis? Clin Infect Dis. 2005;40(12):e113-116.

37. Kopterides P, Papadomichelakis E, Armaganidis A. Linezolid use associated with lactic acidosis. Scand J Infect Dis. 2005;37(2):153-154.

38. Apodaca AA, Rakita RM. Linezolid-induced lactic acidosis. N Engl J Med. 2003;348(1):86-87.

39. Wilson DN, Schluenzen F, Harms JM, Starosta AL, Connell SR, Fucini P. The oxazolidinone antibiotics perturb the ribosomal peptidyl-transferase center and effect tRNA positioning. Proc Natl Acad Sci U S A. 2008;105(36):13339-13344.

40. Thompson J, O'Connor M, Mills JA, Dahlberg AE. The protein synthesis inhibitors, oxazolidinones and chloramphenicol, cause extensive translational inaccuracy in vivo. J Mol Biol. 2002;322(2):273-279.

41. Carson J, Cerda J, Chae JH, Hirano M, Maggiore P. Severe lactic acidosis associated with linezolid use in a patient with the mitochondrial DNA A2706G polymorphism. Pharmacotherapy. 2007;27:2771-2774.

42. Soriano A, Miro O, Mensa J. Mitochondrial toxicity associated with linezolid. N Engl J Med. 2005;353(21):23052306.

43. Naranjo CA, Busto U, Sellers EM, Sandor P, Ruiz I, Roberts EA, Janecek E, et al. A method for estimating the probability of adverse drug reactions. Clin Pharmacol Ther. 1981;30(2):239-245. 